\title{
Understanding the Popperian Legacy in Economics
}

\author{
LAWRENCE A. Boland, Simon Fraser University
}

I shall start with two general theses. My first thesis is this.

(1) If anyone should think of scientific method as a way which leads to success in science, he will be disappointed. There is no royal road to success.

My second thesis is this.

(2) Should anybody think of scientific method ... as a way of justifying scientific results, he will also be disappointed. A scientific result cannot be justified. It can only be criticized, and tested.

[Karl Popper 1961/72, p. 265]

Similarly, it is helpful to formulate the task of scientific method as the elimination of false theories (from the various theories tentatively proffered) rather than the attainment of established truths.

[Karl Popper 1945/63, vol 1, p. 285]

From the point of scientific method, ... we can never rationally establish the truth of scientific laws; all we can do is to test them severely, and to eliminate the false ones (this is perhaps the crux of my The Logic of Scientific Discovery).

[Karl Popper 1945/63, vol 2, p. 363]

In the minds of many, Karl Popper is the most important philosopher of science of the twentieth century. For some this is because they love his vision of science as a progressive and critical enterprise, while for others it is because they hate his rude dismissal of any traditional philosophy that would see science as a means of justifying beliefs. Those who love Popper's vision, and think economics should be considered scientific, often think there ought to be a Popperian legacy in economics. Unfortunately, in his many writings Popper is of little help to his economist fans. In his infrequent references to economics, he treats economics so gingerly as to leave considerable doubt about his views of economics or his view of the applicability of his philosophical concerns to the study of economics.

Some of the economists interested in the possibility of a Popperian legacy in economics were brought together in a 1985 symposium to consider the issue. The purpose of this paper is to examine the main results of this symposium as presented in The Popperian Legacy in Economics edited by Neil de Marchi [1988]. ${ }^{1}$ In his summary of the symposium, de Marchi concludes that there is no Popperian legacy [p. 12]. While it is easy to agree with his conclusion, I find the reasons provided in the symposium to be unsatisfactory. Is the absence of a Popperian legacy in economics due to (1) a fault of Popper, (2) the essential nature of economics or (3) a failure of proponents to understand or correctly apply Popper's views? Only one participant seemed to think the absence of a Popperian legacy is entirely due to Popper. The rest seemed to think it is due to one or another peculiarity of economics that distinguishes economics from scientific disciplines such as physics or chemistry. None of these participants were willing to admit that there may have been a failure on the part of economists to understand or correctly apply Popper's views to economics.

Three of the prominent participants of this symposium have major Popperian credentials. There is Terence Hutchison who is credited by almost everyone with being the first to introduce economists to Popper's views in 1938. Although he claims to have tempered his views since then, he still is the strongest advocate of an essential role in economics for Popper's

1 Since I will be focusing primarily on this book [de Marchi 1988], unless specifically noted, all page reference will be to this book. 


\section{Final Draft}

falsifiability. ${ }^{2}$ There is the self-professed 'neo-Popperian' [p. 38] Mark Blaug who is famous for promoting what the participants call 'falsificationism' and for complaining that economists give only lip-service to falsifiability. ${ }^{3}$ And there is Joop Klant, who is considered the leading proponent of Popper's views in economic methodology in the community of European economists. Regrettably, most of the other participants fail to understand Popper's views and thus too often seem willing to throw the baby out with the philosophically dirty bath water.

\section{Criticism of Popper's view of science}

In one sense the critics of Popper's view of science are correct: Popper's view of science does not do a good job of solving the problems that these critics think must be solved. Most of his critics insist that any good philosopher of science must be able to provide criteria by which good theories can be distinguished from bad theories > that is, it must solve the problem of theory choice. $^{4}$ Of course, I think it is silly to criticize Popper for failing to solve problems that he obviously rejects. The root of the issue is the common view that anyone who discusses the philosophy of science must be promoting their form of a 'scientific method' and claiming that, if properly followed, their method will always produce scientifically acceptable results. For some people, the scientific method is needed in order to specify conventional criteria by which one would rationally choose the best theory from a list of competitors. For others it is a means of justifying or verifying the truth of one's prior beliefs. 5

As the above quotations from Popper's well-known work clearly show, he is not promoting or recommending a particular scientific method. Anyone reading Popper's work to find a recommended scientific method is doomed to disappointment. Typically, critics (and even some proponents) identify Popper with a normative view which says that true scientists should go out of their way to make their theoretical statements falsifiable. A superficial reading of Popper would seem to support this identification. Critics will then argue that many scientifically useful statements are not obviously falsifiable and very few scientific propositions are independently falsifiable (i.e. without depending on an assumption of other propositions being true and thereby begging more questions). They thus say it should be concluded that Popper's normative view of science is wrong. ${ }^{6}$ If readers of Popper's early work are more careful to observe the intended audience of his argument, they will find a much more cautious position. Specifically, the

2 Hutchison urges us not to abandon falsifiability as a primary operating rule in economics because economics is ultimately used to support politics and ethics. He argues that falsifiability is an essential tool against dishonesty.

3 Blaug's paper critically examines the methodological views of John Hicks and finds them incoherent.

4 See Tarascio \& Caldwell [1979]. Very many methodologists in economics consider the primary concern of methodology to be that of determining conventional criteria to enable us to choose among competing theories much like consumers choose between apples and oranges. I have often criticized this view of methodology as well as the related view that is concerned with determining the attributes of scientific theories which allows them to be considered contributions to the growth of knowledge [see Boland 1982, Chapter 10 and 1989, Chapters 4 and 5].

5 For a critical discussion of conventionalist criteria, see [Boland 1982, Chapter 1 and 1989, Chapters 4 and 5].

6 Dan Hausman's contribution to the symposium is just such a critique. From my perspective, such criticism seems to be an attempt to sculpture a representation of Popper from a piece of rotten wood. What Hausman's paper does, however, is to whittle the wood down to a square peg which he tries to cram into an analytical philosopher's round hole. Of course, square pegs do not fit into round holes > and Hausman wants us to think it is due to a flaw in the peg. I think it is the fault of the hole. 


\section{Final Draft}

context must always be recognized in his arguments in favor of falsifiability. With regard to the importance of falsifiability, he sees himself arguing against the common view of the 1920s and 1930s that theories are scientific because they are verifiable. And Popper counters that falsifiability rather than verifiability would be a more appropriate means of demarcating science from nonscience [e.g. 1957/65, p. 40]. But Popper is not claiming that falsifiability, as a static attribute of scientific theories, is a sufficient condition for anything. Obviously, many false propositions are falsifiable.

Since almost all of Popper's early discussion of science is concerned with disciplines such as chemistry and physics, there is no question of scientific status, but rather a question of just what makes chemistry or physics scientific. In his early work, he was merely claiming that verifiability, as a means of demarcation, is logically inadequate since every explanation requires universal propositions ${ }^{7}$ which can never be verified (even when true). Such explanatorily essential propositions are, however, at least falsifiable > so, if one wants a means of demarcation then logically one should require falsifiability rather than verifiability. In this context falsifiability is not obviously being promoted as a foundation for a normative scientific method. Besides, to the extent that every explanation involves universal propositions, falsifiability is assured. Unless one is defending verifiability as a means of demarcating scientific explanations, it is hard to imagine how one can fault Popper's view that falsifiability is an essential attribute of any scientific explanation.

\section{Falsifiability in economics}

To the extent that every economic theory, model or explanation involves assumptions in the form of universal propositions, Popper's views are obviously applicable in economics. So what are the alleged problems that arise when one claims that economic explanations should be falsifiable? During the 1985 symposium, the central problem often referred to was what Klant called the 'parametric paradox'. ${ }^{3}$ The paradox seems to be an alleged conflict between the explanatory method of comparative statics and the common presumption that all testing requires constant parameters. While comparative static analysis requires that we change one of the exogenous variables and determine the effect on the endogenous variables (a common example is the calculation of multipliers in macroeconomics), Klant claims that 'If you assume parameters to be variables, you imply that your theory is not falsifiable' [p. 30]. If Klant's parametric paradox is a problem, then it would be a central obstacle to any fulfillment of the requirement of falsifiability in economics. ${ }^{9}$

Personally, I find the acceptance of Klant's claim > that the parametric paradox is a proof that modern economics is essentially unfalsifiable $>$ to be astounding. The reason is that in my 1960s $\mathrm{PhD}$ thesis I required the assumption of the variability of both parameters and exogenous variables so that I could show what it takes to unambiguously refute some typical macro-

$7 \quad$ Such as 'all consumers are maximizers'.

8 The alleged parametric paradox is not explicitly defined in de Marchi's book and Klant points out that it was introduced elsewhere to criticize Samuelson's methodology. Together these considerations make it difficult to understand the reported discussion. In what follows I am conjecturing what the participants understood as Klant's concept of a parametric paradox (Blaug is explicit in his puzzlement and wonders why Klant would promote Popper given the paradox [p. 30]).

The reason why variability of parameters is an issue is probably the recognition that on the one hand in the natural sciences, for all practical purposes, there are many constants (gravitational acceleration at a given height, absolute zero temperature, the speed of light) but on the other hand, as noted by John Hicks, 'there are no such constants in economics' [1979, p. 39]. Judging by the reported discussion, it seems that many feel that Popper's view of falsifiability and testability is thus appropriate only when there are such natural constants. 


\section{Final Draft}

economic models [see Boland 1989, Chapters 2 and 3].

One of the reasons why many people think falsifiability is difficult to apply in economics is the claim (and possible observation) that few if any fundamental theories have ever been empirically refuted. And, presumably, these same people think refutation of fundamental theories in physics is an everyday occurrence. The main difficulty is that methodologists and historians of economics too often are concerned with grand theories rather than the everyday business of economics. The everyday business of economics is more involved with model building and, as is well known, a refutation of a model would seldom constitute a refutation of the theory represented (or presumed) by the refuted model [see Boland 1977 and 1989, Chapter 7; Cross 1982]. ${ }^{10}$ But particular modelling assumptions are refuted or rejected everyday. Whenever a model builder finds that a linear model cannot fit the available data, that linear model is being rejected as refuted, that is, the linear model is considered in some sense false. Similarly, econometricians who reject ordinary least-squares in favor of generalized leastsquares as a means of estimating a model's parameters do so because they have found models based on the former to be false in some important respect. Such considerations would lead me to conclude that a very modest form of falsification is quite commonplace in economics and certainly not inapplicable.

Even if it is accepted that there is a modest form of falsification employed on a regular basis in economics, this does not constitute evidence in favor of a Popperian legacy in economics. The practice of this modest form of falsification is more a consequence of economists accepting Paul Samuelson's methodological prescriptions. And most important, the primary reason for requiring falsifiability is to assure that any verified theories will not be confused with tautologies [see Boland 1977]. Recall that the avoidance of tautologies was one of the main objectives of Hutchison's promotion of falsifiability in his 1938 book. ${ }^{11}$

\section{Attempts to create a Popperian legacy}

In a very interesting paper, de Marchi recounts the history of a group of well-known economists who in the late 1950s and early 1960s explicitly attempted to use Popper's view of science in economics. Their hidden agenda was to push economics beyond the dominating methodological views of the alleged arch-apriorist, Lionel Robbins, who opposed quantification. It did not take them long to declare failure in their Popperian research programme. According to de Marchi, Chris Archibald tried to apply Popper's views to some fundamental theoretical questions but eventually decided that the variability and/or ambiguity of 'parameters' in comparative static explanations implies that refutations are logically impossible. Dick Lipsey was more concerned with emphasizing the role of quantitative testing of economic theories but eventually decided that all testing must be based on statistical models and, according to de Marchi, this led to the conclusion that economic theories are irrefutable. ${ }^{12}$ In both cases, I think a more accurate

10 In Mary Morgan's review of the history of econometrics with respect to whether econometricians have been concerned with refuting or even verifying fundamental economic theories, she notes, 'econometricians have been primarily concerned with finding satisfactory empirical models, not with trying to prove fundamental theories true or untrue' [p. 199].

11 This idea of promoting falsifiability in opposition to tautologies was essentially the focus of the critical argument developed by Klappholz and Agassi in their well-known debate with Hutchison [see Klappholz and Agassi 1959 and Hutchison 1960 as well as Agassi 1971].

12 This reaction to the problem of testing grand theories with specific models is, of course, an instance of the well-known Duhem-Quine thesis [see Cross 1982]. Virtually everyone thinks it means that testing of grand theories is impossible [e.g. p. 20]. I think this is a mistaken conclusion about testing

in economics. Specific general statements can be tested in economics. As Klant points out, even without absolute refutations testing can necessitate adjustments in our general theories [p. 104]. If 
conclusion might be that neither Archibald nor Lipsey understood Popper's views very well. ${ }^{13}$

Almost everything presented at this symposium misses the point of Popper's approach to the philosophy of science. In his introduction de Marchi acknowledges that many of us think that the importance of Popper's work is not that it sees science as an enterprise devoted to the growth of knowledge but that it sees science primarily as an instance of learning by criticism [p. 7]. For many of us, Popper is seen to be interested in science as an ongoing human activity, a process, which is based primarily on a critical attitude. He is not interested in science as a static method of justification or as a formula for success. Unfortunately, hardly anyone pursued this learning aspect of Popper's work.

In my opinion, the role of falsification in the growth of knowledge is promoted by Popper more to emphasize that science is a process than to argue that it embodies a method that assures progress. By his noting that anyone's claimed advance represents more a refutation than anything else, Popper's argument is always against those who think science progresses in a positive, verificationist manner. His idea of progress is more like Socratic learning > namely, one where we always learn by exposing our ignorance (i.e., false theories and beliefs). But most important, he continually notes that the absence of a scientific method (one which would guarantee success) is not a problem since science is an ongoing process which is always going in the right direction.

The idea of emphasizing process and direction sounds to me like Austrian economics. It is easy to see a similar sentiment in Hayek's early emphasis on the market-based price system as an ongoing process where (in the absence of external influence) there is always movement in the right direction (namely, toward an equilibrium where resources are optimally used and everyone is maximizing). Moreover, the competitive price system is best understood as a commendable process even though it may not always reach an equilibrium. Popper similarly wishes us to recognize that it is not a guarantee of the successful attainment of true theories which motivates scientists but that refuting ignorance is always a movement in the right direction.

Market-oriented economists will often observe that by bidding up the price when there is excess demand, demanders always give the right signal and incentive to producers. As a process, the market forms a basis for social coordination that is always moving in the right direction (toward universal maximization). Popper similarly notes that by putting forth falsifiable explanations, scientists are in a position to improve our knowledge by refuting our ignorance. As a mere practical matter it is easy to see that the more falsifiable our explanations, the better will be our opportunity to learn. For Popper, science as an ongoing social enterprise must be based on falsifiable theories since it is devoted to eliminating ignorance even though

one carefully defines the test criteria, it is sometimes possible to test grand theories with specific models subject only to an agreement concerning ordinary test criteria [see further Boland 1989, Chapter 8].

13 De Marchi's paper solved an old puzzle for me. Both Lipsey and Archibald have a reputation for being what some people might call methodologists. Yet,

(a) I met Lipsey many years ago and he told me that he learned everything he knew from my teacher Joseph Agassi. I ran to the library to look up Lipsey's famous book to see what he had to say about methodology. I was very disappointed.

(b) In 1967, or there about, I had a long conversation with Archibald. He tried in vain to convince me to switch my interests from methodology to something > anything > else.

Given their reputations, how was it possible for them to be so far divorced from my understanding? Nevertheless, I credit Archibald with providing me with a very important viewpoint. In our threehour conversation he stressed that if I was going to study or promote the study of methodology, it was my obligation to always show that the methodology I wished to discuss matters to economists. I always try to apply this both as a consumer of methodology and as a methodologist. As a consumer I always ask: What have I learned that matters? As a methodologist I always assume my audience is poised to ask whether methodology can matter. 


\section{Final Draft}

complete elimination may never be achieved.

\section{The rhetoric of Popper's view of science}

As argued above, practicing economists and econometricians refute particular modeling assumptions every day even though they may only wish to be modest and say the assumptions are rejected as not being 'satisfactory' [e.g. pp. 204-8]. Of course, such modesty is merely rhetorical. Moreover, when practicing economists do talk of falsifiability, they are almost always following Paul Samuelson's lead. Rather than a symposium on a Popperian legacy in economics, I think there should be more discussion of the methodological legacy of Samuelson.

It is surprising that with all their talk of the rhetoric of economics, Don McCloskey and Arjo Klamer fail to examine the rhetoric involved in the typical discussion of Popper's view of science in economics or even of philosophy itself. Neither seems to practice what they preach! Although McCloskey does offer his criticisms of Popper's view of science, nowhere does he seem to appreciate the rhetorical aspect of Popper's writings. Specifically, Popper is always willing to put his discussion in the terms of his intended audience (as noted above) and thus one must be very careful to separate Popper's views from those he is debating. McCloskey does engage in a little rhetorical inquiry by accusing the philosophy of science of being 'too thin'. One lesson that I think can be learned from McCloskey's general discussion on the rhetoric of the history of economics and of methodology is that we should not take philosophers of science as seriously as they take themselves. Unfortunately, in response to McCloskey's and Klamer's continued promotion of the rhetoric of inquiry, some of the participants eventually complained that the discussion of the rhetoric of economics was itself wearing thin.

Perhaps McCloskey and Klamer could have devoted some of their time to an inquiry into the rhetoric of the symposium. For example, it might have been possible for the participants to spend some of the symposium's time discussing Popper's 'critical rationalism' [1945/63, Chapter 24], or his logical 'negativism' [1957/65, p. 228], with respect to science as a critical

process. Instead, the participating economists and methodologists seemed to be victims of the rhetoric of Latakos who emphasized the growth of knowledge; thus, they spent too much time on questions of whether neoclassical economics is an 'empirically progressive' research programme [p. 247]. Unfortunately this seemed to be a matter of design since the symposium was almost exclusively limited to the discussion of falsifiability and its relationship to the question of the growth of knowledge [pp. x, 2, 6-7]. Such a limitation allowed only a thin slice of Popper's view of science to be discussed. The thinness of the slice served up by this symposium is distressing to many of us interested in Popper's more general views of science and learning. And silly criticisms of the chosen thin slice of Popper's work seemed to be distressing for some proponents of falsifiability in economics such as Hutchison:

What alarms me is that we are not building on the advances of the 1930s. In some respects, we are going back to the 1930s. The barbarians really were at the gates then, and in some ways they still are. [p. 25]

Judging by the thinness of the discussion of Popper's work in this symposium and the exclusive concern for thin questions such as whether falsifiability should be a guiding rule in economics, I think Hutchison should look around him. The barbarians are no longer at the gates $>$ now they are within the gates.

\section{References}

Agassi, Joseph [1971] 'Tautology and Testability in Economics', Philosophy of Social Science, $1,49-63$

Boland, Lawrence [1977] 'Testability in Economic Science', So. African Journal of Economics, 
$45,93-105$

Boland, Lawrence [1982] The Foundations of Economic Method. London: George Allen \& Unwin

Boland, Lawrence [1986] Methodology for a New Microeconomics. Boston: Allen \& Unwin

Boland, Lawrence [1989] The Methodology of Economic Model Building. London: Routledge

Cross, Rodney [1982] 'The Duhem-Quine Thesis, Lakatos and the Appraisal of Theories in Macroeconomics', Economic Journal, 92, 320-40

de Marchi, Neil (ed.) [1988] The Popperian Legacy in Economics: Papers presented at a Symposium in Amsterdam, December 1985. Cambridge: Cambridge University Press

Hicks, John [1979] Causality in Economics. Oxford: Basil Blackwell

Hutchison, Terence [1960] 'Methodological Prescriptions in Economics: a Reply', Economica, 27 (NS), 158-61

Klappholz, Kurt and Joseph Agassi [1959] 'Methodological Prescriptions in Economics', Economica, 26 (NS), 60-74

Popper, Karl [1945/63] The Open Society and its Enemies. New York: Harper \& Row

Popper, Karl [1957/65] 'Science: Conjectures and Refutations' reprinted in Conjectures and Refutations: The Growth of Scientific Knowledge. New York: Harper \& Row, 1965, 3365

Popper, Karl [1961/72] 'Evolution and the Tree of Knowledge' reprinted in Objective Knowledge: An Evolutionary Approach. Oxford: Oxford University Press, 1972, 256-84

Tarascio, Vincent and Bruce Caldwell [1979] 'Theory Choice in Economics: Philosophy and Practice', Journal of Economics Issues, 13, 983-1006

June 11, 1998 